\title{
One more reason to learn a new language: Testing academic self-efficacy transfer at junior high school
}

\author{
Luke K. Fryer ${ }^{a}$, W. L. Quint Oga-Baldwin ${ }^{b}$ \\ ${ }^{a}$ The University of Hong Kong, Hong Kong \\ ${ }^{\mathrm{b}}$ Waseda University, Japan
}

Article received 28 April 2017/ Revised 10 October / Accepted 28 October / Available online 15 November

\begin{abstract}
Self-efficacy is an essential source of motivation for learning. While considerable research has theorised and examined the how and why of self-efficacy in a single domain of study, longitudinal research has not yet tested how self-efficacy might generalise or transfer between subjects such as mathematics, native and foreign language studies. The current study examined academic self-efficacy (two measurements 10 months apart) in three subjects (mathematics, native language, and foreign language) across students' first year at junior high school. Two studies were conducted, each including three schools (study-A: $n=480 ;$ study-B: $n=398$ ) to support a test and retest of self-efficacy differences and interrelationships across the year of study. Analyses of self-efficacy change presented a general pattern of significant, small declines in students' selfefficacy for all three subjects. Longitudinal latent analyses indicated a consistent moderate predictive effect from foreign language self-efficacy to native language self-efficacy. The pattern of declines, while consistent with research in Western contexts is a source of concern. The transfer of selfefficacy from foreign to native language learning has potential educational and broader psychological implications.
\end{abstract}

Keywords: self-efficacy; mathematics; native language; foreign language; SEM; longitudinal; junior high school 
Fryer et Oga-Baldwin

\section{Introduction}

Self-efficacy is an essential individual difference for students at any level of education (Honicke \& Broadbent, 2016). It mediates and is mediated by constructs that meta-analyses have established as powerful factors for achievement within formal education (e.g., teacher feedback and grade goals; Hattie, 2009). Ability beliefs have been a topic of attention within junior high school education (e.g., P. Chen \& Zimmerman, 2007; Pajares \& Graham, 1999) due in large part to the difficult transitionary (Wigfield, Eccles, MacIver, Reuman, \& Midgley, 1991) and developmental issues (e.g., Eccles et al., 1993; Roeser, Eccles, \& Sameroff, 2000) that surround this period of formal education. The majority of past research in this area has been undertaken in Western contexts (notable exceptions e.g., Bong, 2001), raising questions about other educational systems. Furthermore, while substantial research has examined (Schunk \& Meece, 2006; Usher \& Pajares, 2008) and sought to intervene (e.g., Turner, \& Lapan, 2005; Ramdass \& Zimmerman, 2008; Barber, et al. 2015) in adolescent students' domain specific self-efficacy, cross-domain self-efficacy research has yet to proceed further than cross-sectional examination (Bong, 2001).

While Japanese elementary school education has been the subject of substantial theoretical and empirical research (Cave, 2007; Lewis, 1995; Oga-Baldwin, Nakata, Parker, \& Ryan, 2017; etc.), less is known about the student experience during and in the transition to Japanese junior high school. This gap in our understanding is important at the moment given the on-going national curriculum reforms aimed at preparing Japanese elementary school students for learning English as a foreign language during junior high school (MEXT, 2008, 2016). Japan's strong literacy and mathematics skills (OECD, 2013; 2016), are an area of national pride (Aoki, 2016), with continued emphasis on reading and calculation ability. At the same time, early foreign language education is sometimes viewed with suspicion (Otsu, 2004).

The combination of these attitudes and current national reform efforts (MEXT, 2016), calls for an examination of the relationships between students' beliefs about learning core subjects (mathematics, native and foreign languages) with an eye towards understanding how attitudes for one subject may affect another. Until 2011, teaching English as a foreign language began in junior high school (MEXT, 2008); after this date it was taught in fifth and sixth year of elementary school, and treated as an additional field of study similar to art and music, but with no tests, grades, or assessments. From 2020, English will become a school subject in all elementary schools, with a standardised set of exams before students enter secondary school. It is thus particularly important that research in this area focus on critical periods of study like the transition to middle school prior to the implementation of the new curriculum. First year at secondary school in Japan is therefore an ideal context for such a longitudinal investigation. Results from such an examination might inform educators nationally and internationally regarding links between beliefs about learning core subjects. Findings might also support national curriculum efforts in nearby countries seeking to strike a balance between these important subjects while maintaining their traditional strengths.

The current research therefore undertook two studies to test changes and cross-domain relationships in students' self-efficacy for learning mathematics, native and foreign languages during first-year junior high school. Following this evaluation, the latent longitudinal interconnections between these domains of selfefficacy were tested. In these studies, we aimed to address both broad questions regarding potential declines in first-year junior high school students' self-efficacy beliefs in the context of Japan, as well as more generally assess the potential for transfer between self-efficacy for mathematics, native and foreign language studies during this critical transition to secondary school.

\subsection{Self-efficacy at school}

Self-efficacy is one of the most researched non-cognitive factors within education for two important reasons. The first is its theoretical lineage stretching back to pivotal research regarding the role of expectancy within outcomes, and then being defined (Bandura, 1977), elaborated (Bandura, 1986), and 
rigorously tested across a range of domains (Bandura, 1997). The second reason for its salient role within educational research is its powerful function within both achievement outcomes and its essential covariates (e.g., goal development and pursuit, persistence, effort and self-regulation; see Bandura, 1993; Zimmerman, 2000). Bandura defined self-efficacy as a person's judgement of their ability to organise and execute courses of action to attain a designated goal (Bandura, 1997).

Perhaps one of the greatest challenges to a child's academic self-efficacy is the transition to junior high school. It is essential that any discussion of this topic begin by acknowledging the less tangible, but still relevant, developmental issues children experience during adolescence both at home (Steinberg, 1987) and at school (Eccles, 1999; Wigfield et al., 1991). In addition to these factors, junior high school learning environments present students with an array of social and academic challenges for students' perceived selfefficacy. Within their stage-environment fit programme of research, Eccles and colleagues (e.g., 1993) noted a number of important differences between secondary and elementary school environments which might partially explain declines in students' motivation to learn. For example, secondary school environments often exhibit more teacher control and less opportunity for students to make choices about their learning. Furthermore, public evaluations and ability-groupings are also increasingly common.

An additional issue for children transitioning to secondary school is that a major source of students' academic self-efficacy comes from the grades they receive from their teachers (Bandura, 1993). Secondary school teachers use higher standards to assess students' work than their elementary school counterparts (Eccles \& Midgley, 1989). This issue combined with the lower self-efficacy that many teachers in junior high school report (important for supporting students' adjustment to new learning environments; Zee \& Koomen, 2016), relative to their elementary school counterparts across a broad spectrum of factors (Eccles et al., 1993), means that students face numerous threats to their academic self-efficacy on entering junior high school.

Research with self-efficacy has generally focused on specific subjects such as mathematics or native language competencies (e.g., Pajares \& Graham, 1999; Pajares \& Miller, 1994). Researchers have worked with specific domains of self-efficacy, even measuring self-efficacy for a broad range of junior high school subjects cross-sectionally (Bong, 2001). While less often researched, the role of self-efficacy within foreign language learning is also well recognized. Studies in language learning contexts have indicated that selfefficacy has important predictive relationships with achievement (Mills, Pajares, \& Herron, 2007), students' attributions for success (Hsieh \& Schallert, 2008), and interest in classroom tasks (Fryer, Ainley, \& Thompson, 2016). Connecting this body of research across students' studies, Bong (2001) found support for strong relationships between self-efficacy for foreign language, math and students' native language studies.

Consistent with empirical connections discussed to this point, Bandura (1997) reviewed the conditions wherein competence judgements might generalise across activities. Pajares (1997, p.3) added some detail to this principle of generalisation or transfer across domains: "i.e., the extent to which they relate to, or transfer across, different performance tasks or domains. For example, when differing tasks require similar subskills, judgments of capability to demonstrate the requisite subskills should predict the differing outcomes" and specifically in school contexts, "In school, students' mathematics and verbal self-efficacy may generalize if the skills for each subject have been adequately taught and developed by a competent teacher." Similarly, Schunk and DiBenedetto (2016, p.43) have discussed how this transfer might take place within formal education, "Educational conditions may foster general self-efficacy because school curricula are structured to promote positive transfer-new learning builds on prior learning." They are quick to highlight, however, that "evidence of self-efficacy generality does not refute the domain-specific conceptualisation of self-efficacy." Both Pajares (1997) and Schunk and DiBenedetto (2016) call for research into how and in what situations transfer of self-efficacy takes place. Such research has the propensity to add to our understanding of both the development of self-efficacy beliefs and the competences/skills they are connected to. 
Fryer et Oga-Baldwin

\subsection{Japanese education and language learning}

Empirical research and observational commentaries have noted the humanistic nature of Japanese elementary schools (Cave, 2007; Oga-Baldwin et al., 2017), while secondary schools are notably more rigid in their use of social control (Cave, 2016; Oga-Baldwin \& Fryer, 2018). Consistent with longstanding evidence from research within Western education (e.g., Eccles et al. 1993), students in this setting often suffer a general decrease in quality of motivation to learn beginning in junior high school (Nishimura \& Sakurai, 2017), culminating for some in despondent attitudes toward learning at the end of high school (Berwick \& Ross, 1989; Sakai \& Kikuchi, 2009) and during university (Fryer, et al., 2013).

At the same time, while students' motivation generally decreases throughout secondary school, Japanese students' performance on international tests of literacy and mathematics are consistently strong (OECD, 2016a). We may attribute some of this success to the comparatively high standards set in Japanese schools (Oga-Baldwin \& Fryer, 2018), a feature common to most of the top performing Asian countries (OECD, 2016b). While Japan consistently ranks among the top performers for math, science, and reading (OECD, 2016a), students here also maintain a poor-to-middling rank as learners of foreign languages (Education First, 2016).

As mentioned previously, current policy is focused on improving the quality of foreign language education through earlier introduction (MEXT, 2008, 2016). At the same time, schools are now expected to promote high quality motivation to learn English (Oga-Baldwin \& Nakata, 2014). In practice, teachers are now expected to pay attention to both spoken aspects of the language as well as academic test preparation. Interestingly, one of the explicit goals in the current curriculum is to further develop a greater understanding of Japanese by learning new communication skills and strategies (MEXT, 2008).

There is evidence to suggest that both positive and negative transfer between native and foreign language (both directions) takes place (Cook, 2003), both contrary and consistent with anecdotal concerns regarding the negative implications of adding foreign languages to school curricula (Otsu, 2004). When this transfer is negative, it is referred to as interference. One example of interference is when pronunciation or vocabulary knowledge from a previous language interferes with new pronounciation (see Cheng \& Zhang, 2015, for a recent discussion and investigation). An example of positive transfer is when learning a foreign language's vocabulary supports a deeper understanding of one's native language vocabulary (e.g., Cunningham \& Graham, 2000); this principle extends to the development of reading skills (Gebauer, Zaunbauer, \& Möller, 2013) in both directions, but strongest from foreign to native language reading fluency and comprehension. Gebauer and colleagues (2013) concluded that the salient transfer from foreign to native language skills were a confirmation of Cummins $(1981,1984)$ interdependence hypothesis. This theory suggests reciprocal connections between both languages, but stronger transfer from foreign to native, resulting partly from increased foreign language learning outside of formal school. Given the interdependence of skills development and self-efficacy beliefs, it is reasonable to hypothesise similar relationships for perceived self-efficacy to learn foreign and native languages.

Transfer is not restricted to foreign language, native language, and mathematics; it is a complex area of research essential to understanding how learning across domains and contexts are connected (see Belenky $\&$ Schalk, 2014). Better knowledge of transfer may indicate ways to support integrative knowledge across the formal education experience (McKeough, Lupart, \& Marini, 2013). While support exists for hypothetical transfer between students' self-efficacy for different school subjects, it has not yet been substantively addressed by longitudinal research to the authors' knowledge. Seminal cross-sectional research in Korea (Bong, 2001) observed strong correlations between Mathematics, Korean, and English, suggesting important connections. Research is now needed to test whether transfer across academic domains takes place through students' self-efficacy for learning mathematics, native and foreign language. 


\subsection{The current study}

The current research examined the development of first-year Japanese junior high school students' self-efficacy for learning mathematics, native and foreign language across a year of study. We were interested in both testing the quantitative change in students' self-efficacy for these subjects and their potential cross-sectional and longitudinal relationships. These issues were addressed by conducting a pair of longitudinal studies at two sets of three Japanese junior high schools across one academic year.

Based on the substantial existing research regarding the difficult transition many students experience adapting to junior high school (Wigfield, et al. 1991), decreases in students' self-efficacy were expected across their first year at junior high school (Hypothesis-1). Strong auto-lagged relationships were expected for self-efficacy within each subject, as prior self-efficacy plays an important role in future self-efficacy development in a domain of study (Hypothesis-2). Finally, anecdotal theorising in the Japanese context suggests negative relationships between the increased foreign language studies (and therefore self-efficacy) and both students' mathematics and native language academic self-efficacy (Otsu, 2004). However, given the substantial covariance of the verbal subjects (Japanese and foreign language studies) cross-sectionally (Bong, 2001), evidence of potential positive skills transfer (foreign to native language as well as native to foreign; e.g., Gebauer, Zaunbauer, \& Möller, 2013), theory within the language education domain of crosslinguistic influence (Cummins, 1981, 1984), and socio-cognitive theorising regarding the potential generalising (Bandura, 1993) or transfer (Pajares, 1997) of self-efficacy across domains, we expect positive cross-sectional and longitudinal connections between the self-efficacies for learning the two languages (Hypothesis-3). Figure 1 presents the fully-forward longitudinal latent model we propose to test.

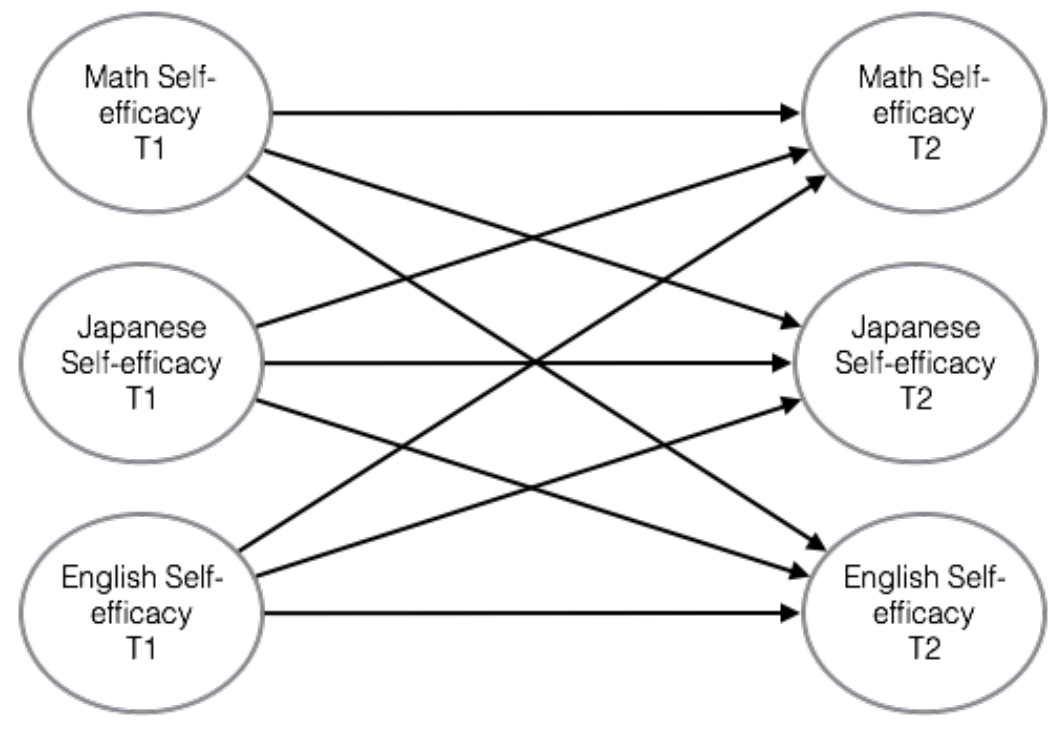

Figure 1. Longitudinal Math, Japanese and English self-efficacy fully-forward model to be tested note: $\mathrm{T} 1$ = Time-1 (May, 2016); T2 = Time-2 (March, 2017) 


\section{Methods}

\subsection{Sample and Context}

For the current research, two studies each collected data from first-year students at three junior high schools in Western Japan: Study A $n=480$ (Female=236) and Study B $n=398$ (Female=186). All students were 12-13 years old. Research participation was coordinated through meetings with the board of education, school principals, and teachers. Student participation was voluntary, and parents were notified regarding student involvement in the study. Six schools located in two rural-suburban districts agreed to participate in the study. The municipalities were largely representative of Japan as a whole (Japan Statistics Bureau, 2017). Surveys for both Study A and B were administered during the 2016-2017 school year, two times and 10 months apart, at the beginning and end of the academic year. Ethical oversight was included in the review process for the JSPS Grant-in-aid for Scientific Research.

\subsection{Instrumentation}

In the current study, self-efficacy for each subject of mathematics, Japanese and English as a foreign language was measured by five items from the patterns of adaptive learning inventory (Midgley et al., 2000). Students self-reported their agreement with scale items (e.g., I am certain I can master the skills taught in class this year; Even if the work is hard, I can learn it) across the Likert formatted scale, from "I don' think so at all" (1) to "I think so" (6). The scale for each subject had a stem to differentiate the items (e.g., In my English class this year...; In my Japanese class this year...; In my mathematics class this year...).

\subsection{Analysis}

Missing data were assessed prior to analyses $(<1 \%)$. Missing data were coded and then accounted for by Full Information Maximum Likelihood estimation within Mplus 7.2 (Muthén \& Muthén, 1998-2015). For both studies in the current research, analyses began with Confirmatory Factor Analysis of each of the three domains of self-efficacy. Fit for the structural equation models were assessed with incremental (Comparative Fit Index; CFI) and absolute (Root Mean Square Error of Approximation; RMSEA) measures model fit. Acceptable/good fit were based on CFI values above .90/.95 (McDonald \& Marsh, 1990) and RMSEA values below .05/.08 (Browne \& Cudeck, 1992).

Analyses then proceeded with reliability (Raykov's Rho; Raykov, 2009) and then invariance estimations. Based on Chen (2007), invariance between Time-1 and Time-2 measures of self-efficacy in the same domain was perceived to be tenable if RMSEA increased by less than .015 and CFI did not change more than .01 .

Latent inter-correlations between all variables and mean differences between Time-1 and Time-2 were calculated for both samples from the two studies. At the final stage, fully-forward structural equation modelling was conducted on both samples (Figure 1). Beta $(\beta)$ coefficients were relied on to interpret structural equation modelling findings. We followed Keith's (2015) suggested guidelines for the interpretation of beta coefficients in research on influences on learning, $\beta$ below 0.05 are interpreted as "too small to be considered meaningful"; those above 0.05 are considered "small but meaningful"; those above 0.10 are considered "moderate"; and those above 0.25 are considered "large". 


\section{Results}

\subsection{Descriptive findings and analysis of changes in self-efficacy perceptions}

Table 1 presents the latent inter-correlations between all variables in each study, A and B. The correlations were predictably strong, but presented no threat of multi-collinearity (i.e., no $r>.90$; Tabachnick \& Fidell, 2007). $t$-tests were conducted (Time1-Time2) for both studies, for each of mathematics, foreign and native language (Bonferroni adjustments undertaken). Both studies presented significant $(p<.01)$, small $(.01>d<.2$; Cohen, 1988; Sawilowsky \& Shlomo, 2003; effect-size calculated using Lakens, 2013) decreases in self-efficacy for each Mathematics, Japanese and English across the yearlong studies. All scales demonstrated excellent reliability in both studies (> .90; Devellis, 2012).

Table 1.

Latent correlations, Means, SDs and Raykov's Rho reliability coefficient for Study A and B

\begin{tabular}{|c|c|c|c|c|c|c|}
\hline & T1 English SE & T1 Math SE & T1 Japanese SE & T2 English SE & T2 Math SE & T2 Japanese SE \\
\hline \multicolumn{7}{|l|}{ T1 English SE } \\
\hline T1 Math SE & $.71 / .72$ & & & & & \\
\hline T1 Japanese SE & $.73 / .73$ & $.72 / .68$ & & & & \\
\hline T2 English SE & $.62 / .59$ & $.48 / .44$ & $.50 / .47$ & & & \\
\hline T2 Math SE & $.46 / .47$ & $.63 / .58$ & $.44 / .47$ & $.64 / 71$ & & \\
\hline T2 Japanese SE & $.52 / .50$ & $.48 / 40$ & $.58 / .55$ & $.69 / .74$ & $.73 / 72$ & \\
\hline Means & $3.83 / 3.75$ & $3.85 / 3.88$ & $3.84 / 3.80$ & $3.78 / 3.53$ & $3.64 / 3.49$ & $3.70 / 3.57$ \\
\hline SDs & $1.24 / 1.18$ & $1.28 / 1.31$ & $1.20 / 1.29$ & $1.23 / 1.18$ & $1.28 / 1.26$ & $1.21 / 1.23$ \\
\hline Raykov's Rho & $.91 / .91$ & $.93 / .94$ & $.93 / .94$ & $.90 / .92$ & $.93 / .94$ & $.94 / .94$ \\
\hline
\end{tabular}

note: Study A / Study B; SE = self-efficacy; T1 = Time-1 (May, 2016); T2 = Time-2 (March, 2017)

\subsection{Construct validity and invariance testing}

For all latent modelling, error covariances were included for items with identical wording crosssectionally. Fit (Table 2) for configural and longitudinal models was acceptable (RMSEA $<.08$, CFI $>.90$ ). Invariance tests for each domain of self-efficacy, for both studies, suggested that the assumption of invariance was tenable (Table 2). 
Table 2.

Fit for Configural, invariance and fully-forward models

\begin{tabular}{llllll}
\hline & $\begin{array}{l}\text { Configural model } \\
\text { test }\end{array}$ & $\begin{array}{l}\text { Japanese } \\
\text { invariance }\end{array}$ & Math Invariance & English Invariance & $\begin{array}{l}\text { Fully-forward } \\
\text { SEM }\end{array}$ \\
& & \multicolumn{2}{c}{ Study A } \\
\hline CFI & .96 & .96 & .96 & .96 & .96 \\
RMSEA & .060 & .061 & .061 & .061 & .060 \\
Chi-Square & $984.224(352)$ & $989.197(356)$ & $985.838(356)$ & $989.198(356)$ & $984.22(352)$ \\
\hline CFI & .97 & Study B & & .97 \\
RMSEA & .050 & .97 & .97 & .055 & .060 \\
Chi-Square & $775.263(352)$ & $776.848(356)$ & $779.56(356)$ & $778.27(356)$ & $775.26(352)$ \\
\hline
\end{tabular}

\subsection{Longitudinal internal and external tests}

The longitudinal fully-forward test of the model (Figure 1) with samples from Study A and Study B presented consistent results. Strong auto-lagged $\beta$ s for all three domains of self-efficacy were observed. A single significant cross-lagged $\beta$ was found in both studies, from Time-1 English to Time-2 Japanese. Figure 2 presents the finalised model with all significant and non-significant $\beta \mathrm{s}$.

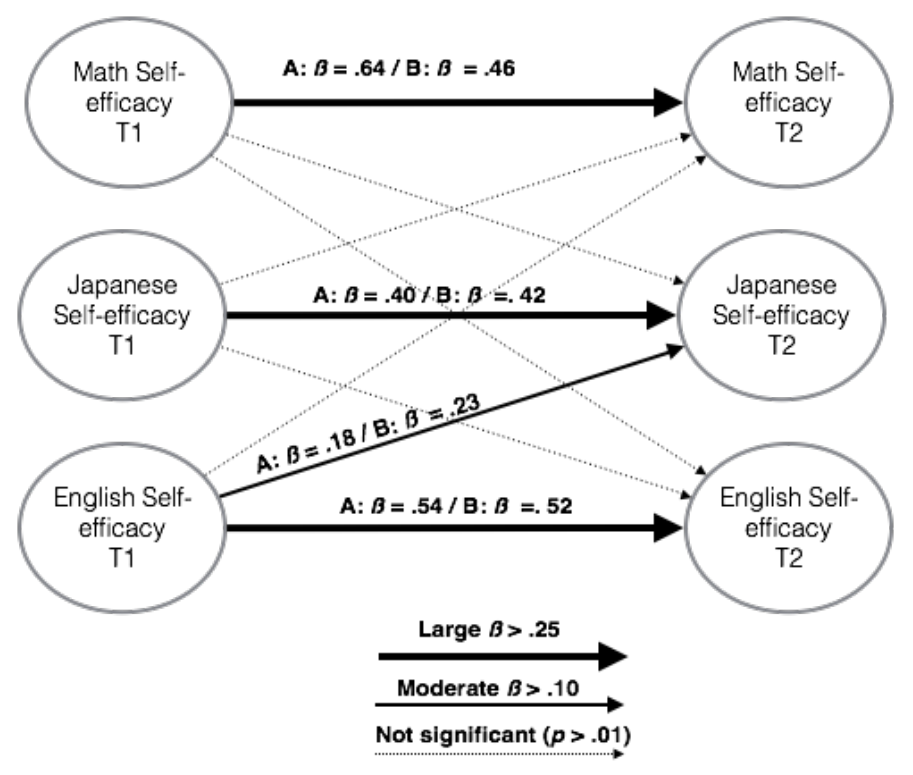

Figure 2. Model test (A) and Replication (B) of mathematics, Japanese, English self-efficacy cross-lagged test

note: No small $\beta$ s were observed. 


\section{Discussion}

The current studies examined the longitudinal differences and relationships between first-year junior high school students' self-efficacy for learning mathematics, Japanese and a foreign language across one academic year. Analysis of self-efficacy change for each subject in both studies confirmed significant small decreases for all three subjects (Hypothesis-1). Large auto-regressive $\beta$ s were observed from all Time- 1 to Time-2 variables (Hypothesis-2). Strong correlations were present between variables cross-sectionally and longitudinally. The only significant cross-lagged $\beta$ s presented by the latent longitudinal model were from foreign language self-efficacy to native language self-efficacy (Hypothesis-3). This final result builds on past cross-sectional findings (Bong, 2001), which, like the present study, indicated substantial cross-sectional relationships between mathematics, native and foreign language academic self-efficacy. These crosssectional findings are narrowed to a singular cross-domain relationship, which suggests transfer from foreign language academic self-efficacy to native language academic self-efficacy.

All of the findings (correlational and changes in self-efficacy beliefs for each subject over time) were consistent across study A and study B, supporting their reliability in the context of Japanese junior high school.

\subsection{Theoretical implications}

While no comparable longitudinal study of academic self-efficacy has been undertaken for the current study to build on, Bong's (2001) study examined similar sources of self-efficacy cross-sectionally. In her study, however, she organised them into verbal and quantitative constructs for an internal/external frame of reference test. While such an organisation is consistent with general theory regarding ability beliefs, the current results suggest the connection between related (verbal) areas of self-efficacy might have a more nuanced relationship than simply converging together on a higher-order factor.

The current studies' results suggest that self-efficacy for a new language supports native language self-efficacy. Essentially, these findings indicate that improving self-efficacy in one domain can support selfefficacy for learning in another close domain (e.g., languages). In the current study, consistent with language learning theory (Cummins, 1981; 1984) and recent reading skills research (Gebauer, et al., 2013) the crossdomain transfer was significant for perceived foreign language learning self-efficacy to perceived native language learning self-efficacy. It is possible, consistent with Cummins theory of language skills transfer, that the dominant connections from foreign to native language self-efficacy might be due to supplementary foreign language studies undertaken outside of school. It might also be the partial result of recent reforms to elementary school English education aimed at stimulating students' interest in foreign language studies, which can in turn support self-efficacy (see Ainley, Buckley, \& Chan, 2009). Replication of the current studies' findings in another context might provide an avenue for overcoming the diminishing returns of prior achievement for future self-efficacy (i.e., Wood \& Bandura, 1989).

The decline observed in students' self-efficacy across three core subjects, in two studies across six junior high schools, is consistent with U.S. findings highlighting the complex transition to junior high school. The current results suggest that, consistent with Western findings (Eccles, 1999; Eccles \& Midgley, 1993), students experienced a decline in important motivations to learn during the transition to secondary school. Further research is necessary to determine what aspects of the learning environment influence selfefficacy and whether this decline persists or is only present during students' first year.

\subsection{Practical implications}

First, it is reasonable to assume that many Japanese junior high school students experience widespread, small declines in self-efficacy for learning during their first year. Several instructional (Zimmerman, 2000) and parenting (Bandura, 1993) strategies are available to support the mitigation of this 
decline. In the classroom, modelling cognitive strategies, helping students set proximal goals and then verbally supporting said goals, and providing frequent feedback on learning activities can play a role in supporting students' self-efficacy. Second, rather than playing a role in the decline of core subjects like native language and mathematics, the current study's latent lagged results suggest that studying a foreign language can have either a non-significant predictive effect (i.e., mathematics) or a substantive predictive positive effect (i.e., native languages) on students' academic self-efficacy. As reviewed, perceptions of selfefficacy are essential predictors of achievement across a broad array of domains, suggesting that enhancing foreign language self-efficacy is one additional means of supporting native language self-efficacy and thereby native language skills.

Our findings suggest that perceived self-efficacy transfer between subjects that rely on similar skills, much like skills and competences themselves, is possible. Specifically, the longitudinal findings from both studies suggest that the transfer is likely to be one way: from foreign to native language self-efficacy. It might therefore be worthwhile for educators' and, more importantly, national curriculum developers' to consider whether students are coming to secondary school with robust self-efficacy for their foreign language studies. Questions regarding the state of students' self-efficacy for foreign language studies when entering secondary school may also have implications for other countries as well. In an interesting and potentially relevant side-note, many countries with strong foreign language skills (notably countries in Northern Europe; Education First, 2016) also score highly on the PISA native language reading test (OECD, 2016a).

\section{Future directions and Limitations}

Further testing at other levels of education in Japan and internationally are called for. It is important for future studies to control for prior achievement as well as self-efficacy. Within the current research programme, latent curve analysis of the full dataset for the current studies in two years (five points) will clarify whether the present results are a part of long- or short-term trends. Longitudinal person-centred analyses are necessary to move beyond mean-based estimates and examine the broader self-efficacy developmental pattern. Finally, quasi-experimental interventions are necessary to assess any attempt at mitigating the declining self-efficacy observed in the current study.

\section{Conclusion}

Substantial research has examined and sought to intervene in students' self-efficacy during junior high school. However, research examining self-efficacy across domains to this point has been constrained to cross-sectional work (i.e., Bong, 2001). In the present longitudinal research, we therefore undertook to examine the interplay of academic self-efficacy across three domains of study. The current study presents two preliminary conclusions for future research to test and build on. Firstly, students experienced broad declines in academic self-efficacy across their first year of junior high school. Second, enhanced selfefficacy for learning a new language predicted the development of greater native language learning selfefficacy. This finding has potentially significant implications for early foreign language learning and selfefficacy development in schools more broadly. In practice, given the widely acknowledged relationship between self-efficacy and both persistence and achievement (Bandura, 1997), anything schools can do to enhance students' self-efficacy for learning a foreign language will not only support the development of a population competent in a second language, but also support students' confidence in their native language learning. 
We encourage examination and replication of our study. If our findings have clear external validity, then Japan and countries in similar situations should consider embarking on truly ambitious foreign language education paths, ensuring students arrive at junior high school with confidence in their second/foreign language. The current pair of studies suggests that we can do this knowing that the experience might, through self-efficacy transfer, also support robust native language skills. The current studies' findings are in alignment with theory (Cummins, 1981, 1984) and empirical research (Gebauer et al., 2013) in the context of second/foreign language learning. They are also consistent with theorising about how self-efficacy might generalise or transfer between sub-skills and domains of study (Bandura, 1997; Pajares, 1997). The present findings therefore have potential implications for how we support student learning in the specific context of native and foreign language studies. Furthermore, we hope these initial findings are enough to get the field thinking about the possibilities such connections create and encourage tests in both a broader range of domains and contexts.

\section{Keypoints}

- Two longitudinal studies examined academic self-efficacy for three subjects during first year at Japanese junior high school

- Students experienced widespread declines in academic self-efficacy during their first year

- Foreign language academic self-efficacy supported native language academic self-efficacy across the first year of junior high school

Analysis of change and latent modelling results were consistent across the two studies conducted

\section{Acknowledgments}

This research was supported by JSPS Grant-in-Aid for Scientific Research (C) 16K02924. 


\section{References}

Ainley, M., Buckley, S., \& Chan, J. (2009). Interest and Efficacy Beliefs in Self-Regulated Learning. In M. Wosnitza, S. Karabenick, A. Efklides, \& P. Nenniger (Eds.), Contemporary motivation research: From global to local perspectives (pp. 207-228).

Aoki, M. (2016, December 6). Japan's 15-year-olds perform well in PISA global academic survey. The Japan Times. http://www.japantimes.co.jp/news/2016/12/06/national/japans-15-year-olds-performwell-pisa-global-academic-survey/

Bandura, A. (1977). Self-efficacy - toward a unifying theory of behavioral change. Psychological Review, 84, 191-215. doi:10.1016/0146-6402(78)90002-4

Bandura, A. (1986). Social foundations of thought and action: A social cognitive theory. New York: Pearson.

Bandura, A. (1993). Perceived self-efficacy in cognitive development and functioning. Educational Psychologist, 28, 117-148. doi:10.1207/s15326985ep2802_3

Bandura, A. (1997). Self-Efficacy: The exercise of control. New York: Freeman.

Berwick, R., \& Ross, S. (1989). Motivation after matriculation: Are Japanese learners of English still alive after exam hell? JALT Journal, 11, 193-210.

Belenky, D. M., \& Schalk, L. (2014). The effects of idealized and grounded materials on learning, transfer, and interest: An organizing framework for categorizing external knowledge representations. Educational Psychology Review, 26, 27-50. doi: 10.1007/s10648-014-9251-9

Bong, M. (2001). Between-and within-domain relations of academic motivation among middle and high school students: Self-efficacy, task value, and achievement goals. Journal of Educational Psychology, 93, 23-34. doi: 10.1037/0022-0663.93.1.23

Browne, M., \& Cudeck, R. (1992). Alternative ways of assessing model fit. Sociological Methods \& Research, 21, 230-258. doi:10.1177/0049124192021002005

Cave, P. (2007). Primary school in Japan: Self, individuality and learning in elementary education. New York: Routledge.

Cave, P. (2016). Schooling selves: Autonomy, interdependence, and reform in Japanese junior high education. Chicago: University of Chicago Press.

Chen, F. F. (2007). Sensitivity of goodness of fit indexes to lack of measurement invariance. Structural equation modeling, 14, 464-504. doi: 10.1080/10705510701301834

Chen, P., \& Zimmerman, B. (2007). A cross-national comparison study on the accuracy of self-efficacy beliefs of middle-school mathematics students. Journal of Experimental Education, 75(3), 221-244. doi:10.3200/jexe.75.3.221-244

Cheng, B., \& Zhang, Y. (2015). Syllable structure universals and native language interference in second language perception and production: positional asymmetry and perceptual links to accentedness. Frontiers in Psychology, 6. doi:10.3389/fpsyg.2015.01801.

Cohen, J. (1988). Statistical power analysis for the behavioral sciences. (2nd ed.) Hillsdale, NJ: Erlbaum.

Cook, V. (2003). Effects of the second language on the first (Vol. 3): Multilingual Matters.

Cummins, J. P. (1983). Heritage language education: A literature review. Toronto: Ministry of Education.

Cummins, J. P. (1984). Bilingualism and special education: Issues in assessment and pedagogy. Clevedon, UK: Multilingual Matters.

Cunningham, T. H., \& Graham, C. R. (2000). Increasing native English vocabulary recognition through Spanish immersion: Cognate transfer from foreign to first language. Journal of Educational Psychology, 92, 37-49. doi:10.1037//0022-0663.92.1.37

Devellis, R. F. (2012). Scale Development: Theory and application (3rd ed.). Thousand Oaks, CA: Sage.

Eccles, J. S. (1999). The development of children ages 6 to 14. Future of Children, 9(2), 30-44. doi:10.2307/1602703

Eccles, J. S., \& Midgley, C. (1989). Stage/environment fit: Developmentally appropriate classrooms for early adolescents. In R. E. Ames \& C. Ames (Eds.), Research on motivation in education (Vol. 3, pp. 139-186). San Diego, CA: Academic Press. 
Eccles, J. S., Midgley, C., Wigfield, A., Buchanan, C. M., Reuman, D., Flanagan, C., \& Mac Iver, D. (1993). Development during adolescence: The impact of stage-environment fit on young adolescents' experiences in schools and in families. American Psychologist, 48, 90-101. doi:10.1037/0003066X.48.2.90

Education First. (2016). EF English proficiency index 2016: Japan. Available from: http://www.ef.co.uk/epi/regions/asia/japan/

Fryer, L. K., Ainley, M., \& Thompson, A. (2016). Modelling the links between students' interest in a domain, the tasks they experience and their interest in a course: Isn't interest what university is all about? Learning and Individual Differences, 50, 157-165. doi:10.1016/j.lindif.2016.08.011

Fryer. L. K., Carter, P., Ozono, S., Nakao, K., \& Anderson, C. J. (2013) Instrumental reasons for studying in compulsory English courses: I didn't come to university to study English, so why should I? Innovation in Language Learning and Teaching. 8, 239-256 doi: 10.1080/17501229.2013.835314

Gebauer, S. K., Zaunbauer, A. C. M., \& Möller, J. (2013). Cross-language transfer in English immersion programs in Germany: Reading comprehension and reading fluency. Contemporary Educational Psychology, 38(1), 64-74. doi:10.1016/j.cedpsych.2012.09.002

Hattie, J. C. (2009). Visible learning: A synthesis of over 800 meta-analyses relating to achievement. London $\&$ New York: Routledge, Taylor \& Francis.

Hsieh, P.-H. P., \& Schallert, D. L. (2008). Implications from self-efficacy and attribution theories for an understanding of undergraduates' motivation in a foreign language course. Contemporary Educational Psychology, 33, 513-532. doi:10.1016/j.cedpsych.2008.01.003

Honicke, T., \& Broadbent, J. (2016). The influence of academic self-efficacy on academic performance: A systematic review. Educational Research Review, 17, 63-84. http://doi.org/10.1016/j.edurev.2015.11.002

Japan Statistics Bureau (2017). Japan statistical yearbook 2017. Available from http://www.stat.go.jp/english/data/nenkan/index.htm.

Keith, T. Z. (2015). Multiple regression and beyond: An introduction to multiple regression and structural equation modelling (2nd ed.). New York: Routledge.

Lakens, D. (2013). Calculating and reporting effect sizes to facilitate cumulative science: A practical primer for t-tests and ANOVAs. Frontiers in Psychology, 4:863. doi:10.3389/fpsyg.2013.00863

Lewis, C. C. (1995). Educating hearts and minds: Reflections on Japanese preschool and elementary education. New York: Cambridge University Press.

McDonald, R. P., \& Marsh, H. W. (1990). Choosing a multivariate model - Noncentrality and goodness of fit. Psychological Bulletin, 107, 247-255. doi:10.1037/0033-2909.107.2.247

McKeough, A., Lupart, J. L., \& Marini, A. (2013). Teaching for transfer: Fostering generalization in learning: Routledge.

MEXT. (2008). Explanatory commentary for the elementary school curriculum guidelines: Foreign language activities. Tokyo: Kyoiku Shuppan.

MEXT. (2016). Gaikokugo waakingu guruupu-niokeru torimatome (an) betten shiryo. Retrieved from http://www.mext.go.jp/b_menu/shingi/chukyo/chukyo3/058/siryo/_icsFiles/afieldfile/2016/09/14/137 3448_1.pdf

Midgley, C., Maehr, M. L., Hruda, L. Z., Anderman, E., Anderman, L., Freeman, K. E., \& Urdan, T. (2000). Manual for the patterns of adaptive learning scales. Ann Arbor, 1001, 48109-41259.

Mills, N., Pajares, F., \& Herron, C. (2007). Self-efficacy of college intermediate French students: Relation to achievement and motivation. Language Learning, 417-442. doi: 10.1111/j.14679922.2007.00421.x/full

Nishimura, T., \& Sakurai, S. (2017). Journal of Applied Developmental Psychology. Journal of Applied Developmental Psychology, 48, 42-48. doi:10.1016/j.appdev.2016.11.004

OECD. (2016a). PISA 2015 Results (Volume I): Excellence and Equity in Education, OECD Publishing, Paris. doi:10.1787/9789264266490-en

OECD. (2016b). PISA 2015 Results (Volume II): Policies and Practices for Successful Schools, OECD Publishing, Paris. doi:10.1787/9789264267510-en 
Oga-Baldwin, W. L. Q., \& Fryer, L. K. (2018). Growing up in the walled garden: Motivation, engagment, and the Japanese educational experience. In G. A. D. Liem \& T. S. Hong (Eds.), Student motivation, engagement, and growth: Asian insights. Routledge.

Oga-Baldwin, W. L. Q., \& Nakata, Y. (2017). Engagement, gender, and motivation: A predictive model for Japanese young language learners. System, 65, 151-163. doi:10.1016/j.system.2017.01.011

Oga-Baldwin, W. L. Q., Nakata, Y., Parker, P., \& Ryan, R. M. (2017). Contemporary Educational Psychology. Contemporary Educational Psychology, 49, 140-150. doi: 10.1016/j.cedpsych.2017.01.010

Otsu, Y. (2004). Is elementary school English necessary? Tokyo: Keio Gijuku Daigaku Shuppan Kai.

Pajares, F., \& Graham, L. (1999). Self-efficacy, motivation constructs, and mathematics performance of entering middle school students. Contemporary Educational Psychology, 24, 124-139. doi: 10.1006/ceps.1998.0991

Pajares, F., \& Miller, M. D. (1994). Role of self-efficacy and self-concept beliefs in mathematical problem solving: A path analysis. Journal of Educational Psychology, 86, 193-203. doi: 10.1037/00220663.86.2.193

Ramdass, D., \& Zimmerman, B. J. (2008). Effects of self-correction strategy training on middle school students' self-efficacy, self-evaluation, and mathematics division learning. Journal of advanced academics, 20(1), 18-41. doi: 10.4219/jaa-2008-869

Raykov, T. (2009). Evaluation of scale reliability for unidimensional measures using latent variable modeling. Measurement and Evaluation in counceling and devlelopment, 42(3), 223-232. doi:10.1177/0748175609344096

Roeser, R. W., Eccles, J. S., \& Sameroff, A. J. (2000). School as a context of early adolescents' academic and social-emotional development: A summary of research findings. Elementary School Journal, 100, 443-471. doi: 10.1086/499650

Sakai, H., \& Kikuchi, K. (2009). An analysis of demotivators in the EFL classroom. System, 37(1), 57-69. doi: 10.1016/j.system.2008.09.005

Steinberg, L. (1987). The impact of puberty on family relations: Effects of pubertal status and pubertal timing. Developmental Psychology, 23, 451-460. doi: 10.1037/0012-1649.23.3.451

Sawilowsky, Shlomo S. (2003). A Different Future For Social And Behavioral Science Research, Journal of Modern Applied Statistical Methods, Vol 2, 128-132. doi: 10.22237/jmasm/1051747860

Schunk, D. H., \& Meece, J. L. (2006). Self-efficacy development in adolescence. In F. Pajares and T. Urdan. Self-efficacy beliefs of adolescents ( $p p$. 71-96). USA: IAP

Schunk, D. H., \& DiBenedetto, M. K. (2016). Self-efficacy theory in education. In K. R. Wentzel \& D. B. Miele (Eds.), Handbook of motivation at school (pp. 34-54). New York, NY: Taylor \& Francis.

Tabachnick, B. G., \& Fidell, L. S. (2007). Using multivariate statistics (5th ed.). Boston: Pearson Education.

Taboada Barber, A., Buehl, M. M., Kidd, J. K., Sturtevant, E. G., Richey Nuland, L., \& Beck, J. (2015). Reading engagement in social studies: Exploring the role of a social studies literacy intervention on reading comprehension, reading self-efficacy, and engagement in middle school students with different language backgrounds. Reading Psychology, 36, 31-85. doi: 10.1080/02702711.2013.815140

Turner, S. L., \& Lapan, R. T. (2005). Evaluation of an intervention to increase non-traditional career interests and career-related self-efficacy among middle-school adolescents. Journal of Vocational Behavior, 66, 516-531. doi: 10.1016:j.jvb.2004.02.005

Usher, E. L., \& Pajares, F. (2008). Sources of self-efficacy in school: Critical review of the literature and future directions. Review of Educational Research, 78, 751-796. doi: 10.3102/0034654308321456

Wigfield, A., Eccles, J. S., MacIver, D., Reuman, D. A., \& Midgley, C. (1991). Transitions during early adolescence changes in childrens domain-specific self-perceptions and general self-esteem across the transition to junior-high-school. Developmental Psychology, 27, 552-565. doi: 10.1037/00121649.27 .4 .552

Wood, R., \& Bandura, A. (1989). Social cognitive theory of organizational management. Academy of Management Review, 14, 361-384. doi: 10.5465/AMR.1989.4279067 
Zee, M., \& Koomen, H. M. Y. (2016). Teacher self-efficacy and its effects on classroom processes, student academic adjustment, and teacher well-being. Review of Educational Research, 86, 981-1015. doi:doi:10.3102/0034654315626801

Zimmerman, B. J. (2000). Self-efficacy: An essential motive to learn. Contemporary Educational Psychology, 25, 82-91. doi:10.1006/ceps.1999.1016 